\title{
Effect of the Particle Size of Cladding Materials on the Morphology and Corrosion Resistance of Fe-based Laser Cladding Layers
}

\author{
Chuanwei Shi ${ }^{*}$ Peng Liu, Dongfang Yan, Yuanbin Zhang
}

School of Materials Science and Engineering, Shandong Jianzhu University, Jinan, China *E-mail: shichuanwei@sdjzu.edu.cn

doi: $10.20964 / 2020.02 .17$

Received: 7 September 2019 / Accepted: 22 November 2019 / Published: 31 December 2019

Fe-based laser cladding layers were reinforced by TiC with different morphologies prepared in situ by using FeTi30 powder, graphite powder, and Fe-based self-fluxing alloy powder with different particle sizes. The effects of the particle size of the cladding alloy powder on the TiC morphologies, and the hardness and corrosion resistance of the reinforced Fe-based cladding layers were studied by X-ray diffraction, scanning electron microscopy, and an electrochemical workstation. The results showed that as the particle size of the cladding alloy powder decreased under the same laser cladding process, the cladding layer showed a better form, and there were no changes in the cladding layer phase. The TiC morphology changed from a large petal shape to a polygonal block. The hardness of the cladding layer decreased, but the corrosion resistance of the cladding layer increased.

Keywords: laser cladding; TiC; corrosion resistance; powder size

\section{FULL TEXT}

(C) 2020 The Authors. Published by ESG (www.electrochemsci.org). This article is an open access article distributed under the terms and conditions of the Creative Commons Attribution license (http://creativecommons.org/licenses/by/4.0/). 